\title{
Nerve collagens from diabetic and nondiabetic Sprague-Dawley and biobreeding rats: an atomic force microscopy study
}

H. Wang ${ }^{1}$

B. E. Layton ${ }^{2}$

A. M. Sastry ${ }^{1,2 *}$

${ }^{1}$ Department of Mechanical

Engineering, The University of

Michigan, Ann Arbor, Michigan, USA

${ }^{2}$ Department of Biomedical

Engineering, The University of

Michigan, Ann Arbor, Michigan, USA

*Correspondence to: A. M. Sastry, Department of Mechanical

Engineering, Ann Arbor, MI, USA.

E-mail: amsastry@umich.edu
Received: 22 July 2002

Revised: 20 December 2002

Accepted: 14 January 2003

\begin{abstract}
Background Alterations in rat's nerve collagens due to diabetes may be related to the permanence of damage due to diabetic neuropathy. We (1) provide a methodology for determining the diameters of collagen fibers accounting for atomic force microscope (AFM) imaging artifacts, (2) present data on structural differences in sciatic nerve endoneurial, epineurial and tail tendon collagens of control and diabetic Sprague-Dawley and BioBreeding rats, and (3) compare results with literature values.
\end{abstract}

Methods We measured collagen diameters and band spacing on endoneurial and epineurial sciatic nerve tissue, and tail tendon, in control and diabetic rats (STZ-induced 12-week diabetic SD and 16-week spontaneously diabetic $\mathrm{BB}$ rats). We also developed a model to interpret the raw AFM data.

Results All types of fibrillar collagen diameters studied became larger for diabetic versus control animals. Values for diabetic and control collagen fiber diameters in SD rats were $78 \mathrm{~nm}$ and $72 \mathrm{~nm}$ for SN epineurium, and $49 \mathrm{~nm}$ and $43 \mathrm{~nm}$ for SN endoneurium. For diabetic and control BB rats, these values were $83 \mathrm{~nm}$ and $77 \mathrm{~nm}$ (SN epineurium) and $49 \mathrm{~nm}$ and $43 \mathrm{~nm}$ (SN endoneurium). Values of $161 \mathrm{~nm}$ and $125 \mathrm{~nm}$ were found for diabetic and control tail tendon of BB rats. No significant changes were observed in any of the five comparisons made in D-band spacings that ranged from 63 to $69 \mathrm{~nm}$.

Conclusions The best means we have found to reduce raw AFM data is to measure several diameters with a single scan, using valley-to-valley measurements. Structural, fibrillar collagens of the nerve and tendon become larger in rats exposed to prolonged diabetes. Copyright (c) 2003 John Wiley \& Sons, Ltd.

Keywords diabetes; BB rat; SD rat; collagen; atomic force microscope; AFM; tip artifacts

\section{Introduction}

\section{Collagens in diabetic neuropathy}

It has been speculated that diabetic neuropathy is a direct consequence of hyperglycemia or other metabolic consequences of insulin deficiency [1]. For example, the results of the DCCT [2], conclusively established that intensive diabetes management with insulin reduces the risk of developing clinically overt, objectively confirmed diabetic polyneuropathy (DPN). However, it is 
presently unclear whether the onset of diabetic neuropathy is simply the result of advanced glycation product mechanisms (AGE) $[3,4]$ or a stress-state induced mechanism, as has been observed in other tissues such as the skin [5].

Structural changes have been observed in fibrillar collagens in the presence of diabetic neuropathy in vivo $[6,7]$, and in the presence of high glucose concentrations in vitro [3]; these tissue changes may ultimately provide insight into the pathogenesis and permanence of damage associated with DPN.

Normal anatomy of the peripheral nerve is shown in Figure 1(a) and of the tail in Figure 1(b). Fibril diameter increases with radial distance from the nerve or fascicle center with smaller fibrils found in the endoneurium and larger fibrils found in the epineurium [8].

Clinical studies quantifying structural differences in fibrillar collagens between control (Table 1) and diabetic (Table 2) humans and rats [9-16] have employed scanning and transmission electron microscopy (SEM and TEM) and atomic force or scanning probe microscopy (AFM or SPM, referred to hereafter as AFM). The first evidence of the presence of larger collagen fibril diameters in diabetic sciatic nerve was presented by Muona et al. [16] who measured endoneurial collagen fibrils in spontaneously diabetic BioBreeding (BB) rats using TEM. These distal tissues are of high interest since they are presumed to be the most affected by DPN. Johnson et al. [17] observed thickened basement membranes in human diabetic endoneurium and perineurium with TEM. Bradley et al. [6] observed similar changes in endoneurial fibrils in human sural nerves, with TEM. Odetti et al. [15] found, via AFM, enlarged tail collagen fibril diameters in diabetic $\mathrm{BB}$ rats. The purpose of this study was to confirm and expand upon the findings of Muona et al. [16] and Bradley et al. [6]. We used a technique similar but not identical to that of Odetti et al. [15].

In summary, collagen fibrillar structure and type have both been observed to change in the presence of diabetic neuropathy in animals and humans. Because of the ease of sample preparation and the ability to map threedimensional structure, AFM remains a very attractive technique for these assays. However, artifacts induced by
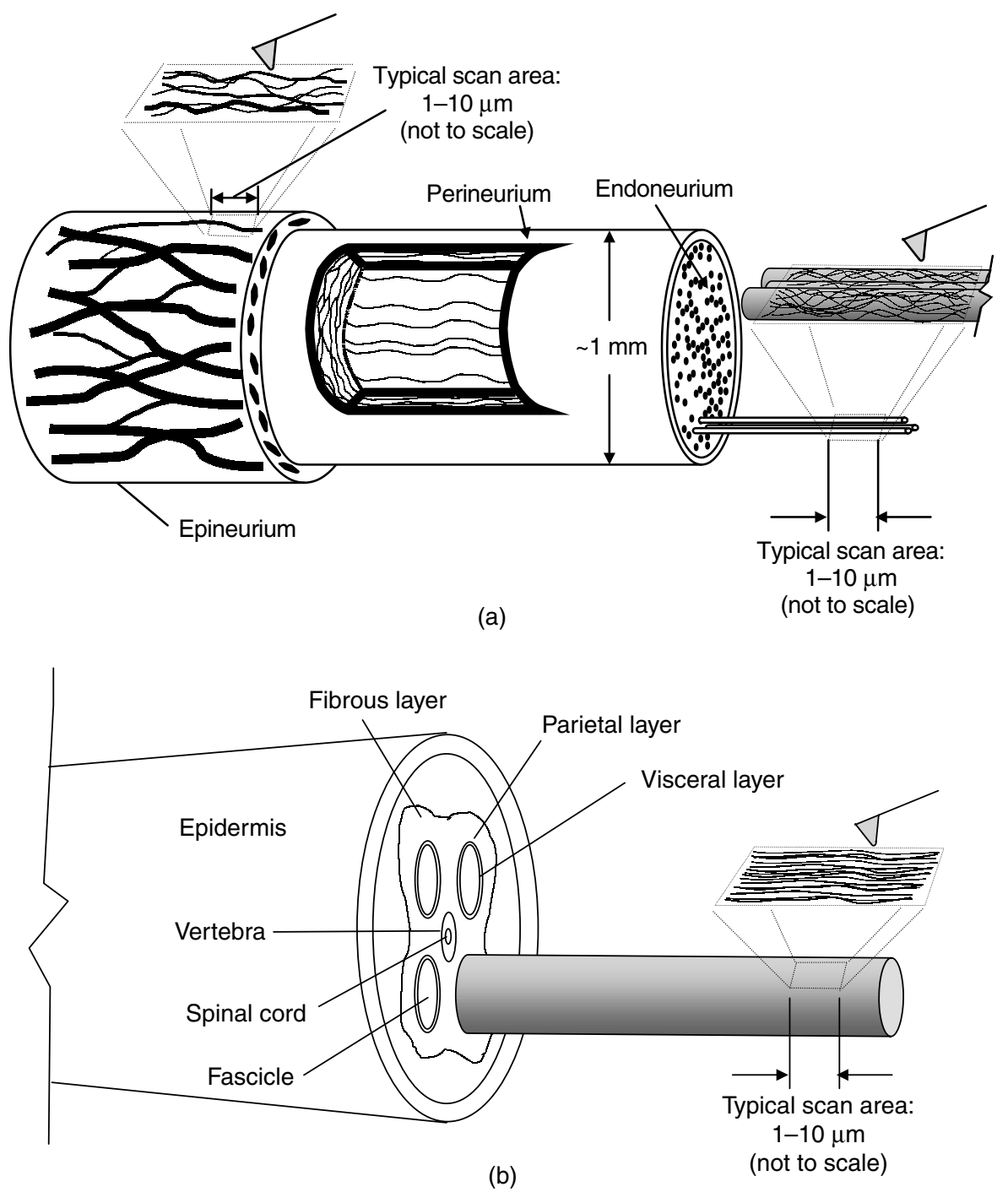

Figure 1. Normal anatomy of (a) rat sciatic nerve and (b) rat tail tendon 
Table 1. Previously reported values for normal collagen diameters from rat and human nerve and tendon

\begin{tabular}{|c|c|c|c|c|c|c|}
\hline Year & Author & Method & Animal & Tissue & Location & Diameter (nm) \\
\hline 1998 & Baranauskas et al. [5] & AFM & Rat & Achillies $\mathrm{t}$. & n.g. & $124-170$ \\
\hline 1997 & Gotoh et al. [18] & $\begin{array}{l}\text { TEM } \\
\text { SEM }\end{array}$ & Rat & Tail t. & Fibrous layer & $30-120$ \\
\hline 1994 & Revenko et al. [10] & AFM & Rat & Tail t. & n.g. & $100-200$ \\
\hline 1990 & Ushiki et al. [11] & $\begin{array}{l}\text { TEM } \\
\text { SEM }\end{array}$ & Rat & Sciatic $n$. & $\begin{array}{l}\text { Epineurium } \\
\text { Perineurium } \\
\text { Endoneurium }\end{array}$ & $\begin{array}{l}30-100 \\
30-60 \\
40-45\end{array}$ \\
\hline 1985 & Gotoh and Sugi [12] & SEM & Rat & Tail t. & Fascicle & $318 \pm 12$ \\
\hline 1964 & Gamble and Eames [13] & TEM & Human & $\begin{array}{l}\text { Medial cutaneous n., } \\
\text { Brachial plexus, } \\
\text { Median } \mathrm{n} \text {. }\end{array}$ & $\begin{array}{l}\text { Endoneurium } \\
\text { Perineurium } \\
\text { Epineurium }\end{array}$ & $\begin{array}{l}30-65 \\
40-80 \\
60-110\end{array}$ \\
\hline 1963 & Thomas [14] & TEM & Rabbit & $\begin{array}{l}\text { Gastrocnemius } \\
\text { Gastrocnemius }\end{array}$ & $\begin{array}{l}\text { Epineurium } \\
\text { Endoneurium }\end{array}$ & $\begin{array}{l}70-85 \\
50-60\end{array}$ \\
\hline & & SEM & Bovine & Cornea & Sub.propria & 50 \\
\hline 1942 & Schmitt et al. [7] & $\begin{array}{l}\text { SEM } \\
\text { SEM } \\
\text { SEM }\end{array}$ & $\begin{array}{l}\text { Kangaroo } \\
\text { Frog } \\
\text { Squid }\end{array}$ & $\begin{array}{l}\text { Tail t. } \\
\text { Achilles t. } \\
\text { Giant axon }\end{array}$ & $\begin{array}{l}\text { n.g. } \\
\text { n.g. } \\
\text { Axonal }\end{array}$ & $\begin{array}{l}160-400 \\
85 \\
40\end{array}$ \\
\hline
\end{tabular}

Table 2. Previously reported values for collagen diameters from diabetic and HMSN rat and human nerve and tendon

\begin{tabular}{|c|c|c|c|c|c|c|c|c|c|c|}
\hline Year & Author & Animal & Method & Condition & Duration & Tissue & Location & Diabetic (nm) & Control (nm) & $p$-value \\
\hline 2000 & Bradley et al. [6] & Human & TEM & Diabetic & Years & Sural $n$. & Endo & $58.4 \pm 1.1$ & $51.4 \pm 1.2$ & $<0.008$ \\
\hline 2000 & Bradley et al. [6] & Human & TEM & HMSN & Years & Sural $n$. & Endo & $63.8 \pm 5.2$ & $51.4 \pm 1.2$ & $<0.008$ \\
\hline 2000 & Odetti et al. [15] & BB rat & AFM & Diabetic & 12 wks & Tail t. & n.g. & $472 \pm 6$ & $302 \pm 2$ & $<0.001$ \\
\hline 1989 & Muona et al. [16] & BB rat & TEM & Diabetic & $2.5-6 \mathrm{mo}$ & Sciatic n. & Endo, prox, & 52.6 & 46.1 & $<0.001$ \\
\hline & & & & & & & Endo, distal & 52.4 & 45.5 & $<0.001$ \\
\hline
\end{tabular}

tip interaction must be accounted for in reducing data and in comparing results by various groups.

\section{Atomic force microscopy: artifacts and models}

Since its invention [19], the atomic force microscope has become an important tool in assaying the structure of biological materials [20]. Morris et al. [21] have provided a complete review of biological applications of AFM. A unique advantage of AFM for biological research is its ability to resolve topological features at the atomic scale without significant disruption of tissue.

Indeed, the technique has been used extensively to measure structural changes in collagen fibrils, as summarized in the previous section [15,22-24]. Unlike EM images, however, AFM images must generally be corrected for artifacts arising from finite tip sizes, cantilever angle and tip placement on the cantilever. Development of more general models for AFM tip interactions remains an area of active research (e.g. [25-32]).

Odetti et al. [15] recently presented measurements of the width and $\mathrm{D}$-band depth of tail tendon collagen fibril diameter from $\mathrm{BB} / \mathrm{Wor} / \mathrm{Mol} / \mathrm{BB}$ male rats in AFM contact mode. Radii of curved segments from section profiles were used to determine diameters. The tip effects were judged to be unimportant in that methodology since the fibril radii were five times greater than the tip radii used. Kato et al. [24] measured type I collagen fibril diameters and D-band spacing in air and aqueous solution via the
AFM. The tip effects were considered and the diameters of fibrils were estimated using a model similar to an earlier one provided by Odin et al. [26].

In this paper, artifacts resulting from AFM tip geometry were modeled and an imaging method was developed on the basis of the observed arrangement of fibrils in rat sciatic nerve and tail tendon. Most of the epineurial fibrils observed in this study were axially oriented in wavy bands, as previously observed by Ushiki and Ide [11]. Endoneurial collagen fibrils in the outer layer along the nerve fibers were also aligned, as observed by Ushiki and Ide [11] and Friede and Bischhausen [33]. Since AFM scans only the sample surface, our method did not reveal the inner 'lacework' observed in [11,33]. Generally, we observed clustered fibrils as also seen in $[9,15,22]$. Thus, we took an approach similar to that of Garcia et al. [30], in which several particles were imaged in a single scan for data analysis; we did not attempt to image single fibrils as in $[10,23,24,34]$. Modeling details are provided in the Appendix.

\section{Materials and methods}

\section{Specimen collection and imaging}

Two clinical studies were performed on diabetic and control BioBreeding (BB) rats and diabetic, weight control and control Sprague-Dawley (SD) rats. Ten diabetic and 8 control, 18-week-old male BB (Biomedical Research Models, Worchester, MA, USA) rats, and 27 age-matched 
9-week-old male SD rats (Charles River Labs Cambridge, MA, USA) were used. Each animal weighed approximately $300 \mathrm{~g}$. All rats were purchased and cared for according to University, State, and Federal standards in accord with the National Research Council's 'Guide for the Care and Use of Laboratory Animals.' Additionally, BB rats were cared for using cared Guberski's [35] husbandry guidelines. Diabetes was induced with 50 to $55 \mathrm{mg} / \mathrm{kg}$ in 12 SDs and 8 SDs were used as weight controls. Body weights were taken (BB daily, SD weekly) with an Ohaus triple-beam balance (Fisher). Blood glucose values were from the tip of the tail, and analyzed using a One-Touch glucose monitor (LifeScan, Johnson and Johnson) [36]. The diabetic BBs had blood glucoses in excess of $150 \mathrm{mg} / \mathrm{dL}$ upon arrival, after 8 weeks of diabetes, and were maintained near $300 \mathrm{mg} / \mathrm{dL}$ for an additional 8 weeks. Animals were euthanized using $0.08 \mathrm{mg} / \mathrm{g}$ pentobarbital sodium (Vortech Pharmaceuticals, Dearborn, MI). After 12 weeks, the SD rats had an average blood glucose of $341 \pm 60 \mathrm{mg} / \mathrm{dL}$ (diabetic rats) and $100 \pm 18 \mathrm{mg} / \mathrm{dL}$ (controls), and after 16 weeks, the BB rats had an average blood glucose of $380 \pm 21 \mathrm{mg} / \mathrm{dL}$ (diabetic rats) and $60 \pm 5 \mathrm{mg} / \mathrm{dL}$ (controls).

Nerves were obtained from the euthanized SD and $\mathrm{BB}$ rats. Endoneuria were gently removed, placed on freshly cleaved mica, and imaged in air contact mode with a Dimension 3000 BioScope (Digital Instruments, Santa Barbara, California). Endoneuria were left intact, with axons aligned. Collagens ensheathing the axons were imaged (Figure 1a). Epineuria were also cut and opened carefully, and outer surfaces were imaged. Care was taken to place epineuria on mica in nearly their original, unstretched state (Figure 1a).

In the $\mathrm{BB}$ rats, $1 \mathrm{~cm}$ of distal tail was removed and a portion of tendon, within one or two vertebra of the tip, was imaged. The skin was opened with a scalpel exposing four tendons surrounding the vertebra. One of the four was selected and a section approximately 5-mm long was opened, revealing the fibrous layer fibrils [18]. These were placed in phosphate buffered saline and allowed to dry on freshly

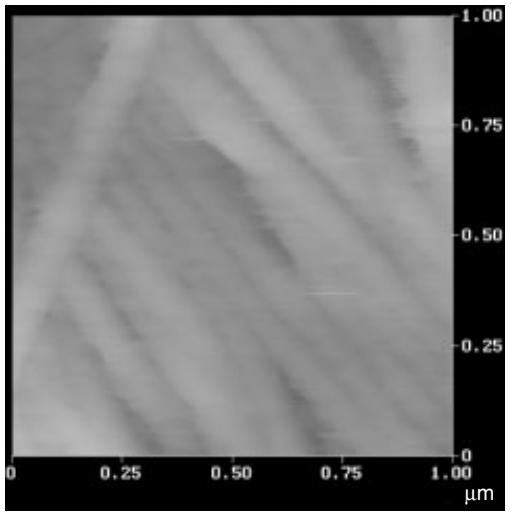

(a) cleaved mica before imaging. See Figure 1(b). Specimen sizes for the epineurium, the endoneurium, and the tail tendon were approximately $2 \times 1 \times 0.1 \mathrm{~mm}, 4 \times$ $0.2 \times 0.1 \mathrm{~mm}$, and $2 \times 1 \times 0.1 \mathrm{~mm}(l \times \mathrm{w} \times \mathrm{h})$, respectively. Scan sizes of $10 \mu \mathrm{m}, 2 \mu \mathrm{m}$, and $1 \mu \mathrm{m}$ were performed for epineurial, endoneurial, and tail tendon tissues.

A Digital Instruments (DI) Model BS-3 Bioscope (Digital Instruments, Inc., Santa Barbara, CA) equipped with a $120-\mu \mathrm{m}$ j-scanner loaded with V-shaped silicon nitride NanoProbe SPM tips (DI) with nominal spring constant 0.12 or $0.06 \mathrm{~N} / \mathrm{m}$ was used to image tissues. Cantilevers were $200-\mu \mathrm{m}$ long and $0.6-\mu \mathrm{m}$ thick with square pyramidal $35^{\circ}$ half-angle tips with a nominal radius of 20 to $60 \mathrm{~nm}$. Integral and proportional gains were set to 2.0 and 3.0, respectively. The scan rate was approximately $1 \mathrm{~Hz}$. The deflection set point was adjusted during the imaging process to minimize contact force.

AFM images were not processed or filtered and were exported with false color to represent height. Digital Instrument's cross section analysis tool was used, post-scanning, to measure collagen fibril diameters. In Figure 2, representative AFM images of epineurial collagen from (1) control and (2) diabetic BB rat sciatic nerves are shown. We observed clustering of collagen fibrils rather than single, isolated fibrils, either as offset or collinear cylinders. This observation is consistent with those of several other workers (e.g. [11]). Thus, our modeling approach was restricted to multiple measurements of either aligned or misaligned cylinders; in most cases, between one and three fibrils were used for these measurements. To ensure that diameters were measured orthogonally to fibril axes, we sampled 3-D image data at several angles and verified that minimum values were obtained. As a test of reproducibility, two sets of measurements were performed on each fibril or fibril bundle to assure orthogonality of the line of measurement to the fibril or bundle axis.

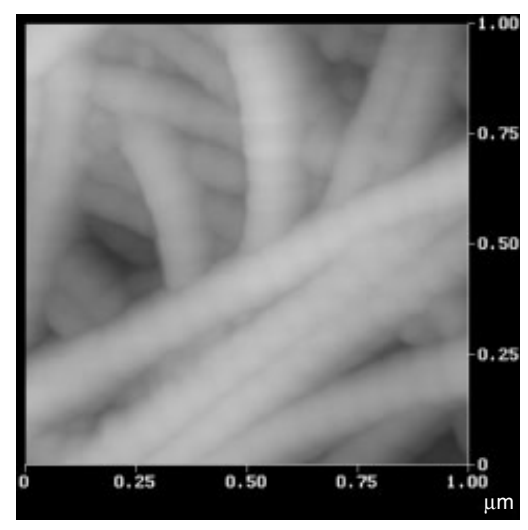

(b)

Figure 2. Atomic force microscopy image of (a) epineurial collagen from a control BioBreeding rat sciatic nerve and (b) epineurial collagen from a diabetic BioBreeding rat sciatic nerve 


\section{Results}

\section{Tip artifact corrections}

Corrected and uncorrected values for collagen fibrils are presented in Table 3. The student's one-tailed heteroscedastic t-test in Microsoft ${ }^{\circledR}$ Excel [37-39] was used to test statistical significance in all comparisons, except for D-banding, in which a two-tailed test was used. We only report data in which error was found to be less than $1 \%$. We found corrections of approximately 45 and $95 \%$ in SD measurements, and 39 and $69 \%$ in BB measurements, of endoneurial and epineurial collagens, respectively. In BB tail collagens imaged, these corrections were approximately, 10 and 24\%, for control and diabetic animals.

\section{SD collagens: findings}

\section{Epineurium}

The measured average diameter for epineurial collagen fibrils was $77.9 \pm 10.1 \mathrm{~nm}$ for diabetic rats and $72.1 \pm$ $12.9 \mathrm{~nm}$ for controls.

\section{Endoneurium}

Figure 3 shows an axon with an approximate width of $15 \mu \mathrm{m}$. The axons are ensheathed in a layer of collagen fibrils. The measured averaged diameters for endoneurial collagen fibrils were $49.5 \pm 9.4 \mathrm{~nm}$ for diabetic rats and $42.0 \pm 9.0 \mathrm{~nm}$ for controls.

\section{BB collagens: findings}

\section{Epineurium}

The averaged diameter for diabetic epineurial collagen fibrils was $82.9 \pm 15.9 \mathrm{~nm}$ and for controls it was $76.6 \pm 13.8 \mathrm{~nm}$. The $p$-values between the two groups of data are $<0.001$.

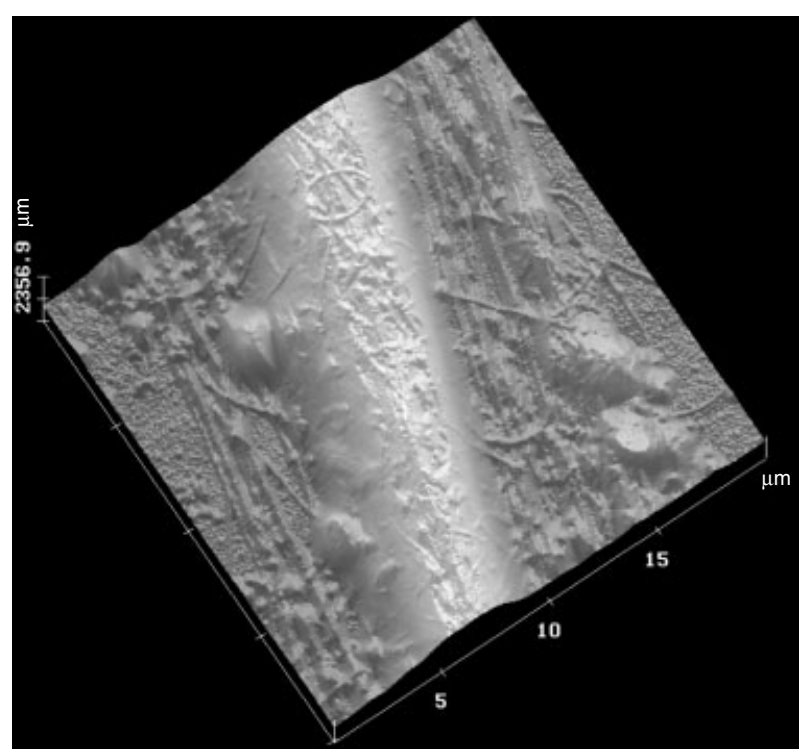

Figure 3. A collagen-ensheathed axon from a control Sprague-Dawley rat sciatic nerve

\section{Endoneurium}

Using the same measurement technique as in the epineurial collagen, the averaged diameter for endoneurial collagen fibrils was found to be $49.1 \pm$ $9.9 \mathrm{~nm}$ for diabetic rats and $42.9 \pm 4.9 \mathrm{~nm}$ for controls. The $p$-values between the two groups of data are less than 0.001 .

\section{Tail}

The BB tail tendon collagen fibrils were measured using the same technique as for the Sprague-Dawley tissues. We found the collagen fibrils of the fibrous layer to have diameters in the range of 40 to $220 \mathrm{~nm}$ for both control and diabetic samples. Diameters are reported in Table 3.

\section{Banding periodicity}

An investigation of D-banding was performed on all tissues. No significant differences were found among any

Table 3. Results for Sprague-Dawley and BB epineurial and perineurial, and BB tail collagen fibril diameters: average $\pm \sigma$ (standard deviation, normal distribution)

\begin{tabular}{|c|c|c|c|c|c|c|c|c|c|}
\hline Animal & Duration & Tissue & Location & Diabetic (nm) & $\begin{array}{c}\text { Control } \\
(\mathrm{nm})\end{array}$ & $\begin{array}{l}\text { w control } \\
(\mathrm{nm})\end{array}$ & $\begin{array}{c}p \\
d v c\end{array}$ & $\begin{array}{c}p \\
c \vee w\end{array}$ & $\underset{d v w}{p}$ \\
\hline SD rat & 12 Weeks & Sciatic nerve & $\begin{array}{l}\text { Epi } \\
\text { Endo }\end{array}$ & $\begin{aligned} 114 & \pm 56^{a} \\
78 & \pm 9(24) \\
95 & \pm 38^{\mathrm{a}} \\
49 & \pm 9(45)\end{aligned}$ & $\begin{aligned} 104 & \pm 37^{a} \\
72 & \pm 13(34) \\
83 & \pm 17^{a} \\
43 & \pm 6(21)\end{aligned}$ & $\begin{aligned} 103 & \pm 35^{a} \\
72 & \pm 9(78) \\
70 & \pm 13^{a} \\
42 & \pm 6(73)\end{aligned}$ & $\begin{array}{l}\text { n.d. } \\
0.055 \\
\text { n.d. } \\
\underline{0.001} \\
\end{array}$ & $\begin{array}{l}\text { n.d. } \\
0.432 \\
\text { n.d. } \\
0.478\end{array}$ & $\begin{array}{l}\text { n.d. } \\
\begin{array}{l}0.016 \\
\text { n.d. } \\
\leq 0.001\end{array}\end{array}$ \\
\hline BB rat & 16 Weeks & Sciatic nerve & $\begin{array}{l}\text { Epi } \\
\text { Endo }\end{array}$ & $\begin{aligned} 117 & \pm 27^{\mathrm{a}} \\
83 & \pm 16(386) \\
75 & \pm 22^{\mathrm{a}} \\
49 & \pm 10(180)\end{aligned}$ & $\begin{aligned} 105 & \pm 35^{\mathrm{a}} \\
77 & \pm 14(236) \\
75 & \pm 16^{\mathrm{a}} \\
43 & \pm 5(151)\end{aligned}$ & & $\begin{array}{l}\text { n.d. } \\
0.001 \\
\begin{array}{l}\text { n.d. } \\
\leq 0.001\end{array}\end{array}$ & & \\
\hline BB rat & 16 Weeks & Tail tendon & Distal & $\begin{array}{l}177 \pm 26^{a} \\
161 \pm 41(76)\end{array}$ & $\begin{array}{l}155 \pm 31^{a} \\
125 \pm 33(45)\end{array}$ & & $\begin{array}{l}\text { n.d. } \\
\leq 0.001\end{array}$ & & \\
\hline
\end{tabular}

n.d. (not done).

adenotes raw, uncorrected data not measured with the valley-to-valley method. 
Table 4. Results for Sprague-Dawley and BB epineurial and perineurial, and BB tail collagen fibril D-banding: average $\pm \sigma$ (standard deviation, normal distribution)

\begin{tabular}{|c|c|c|c|c|c|c|c|c|c|}
\hline Animal & Duration & Tissue & Location & Diabetic (nm) & Control (nm) & $\begin{array}{c}\text { w control } \\
(\mathrm{nm})\end{array}$ & $\begin{array}{c}p \\
d v c\end{array}$ & $\begin{array}{c}p \\
c \vee w\end{array}$ & $\begin{array}{l}p \\
d v w\end{array}$ \\
\hline SD rat & 12 weeks & Sciatic nerve & $\begin{array}{l}\text { Epi } \\
\text { Endo }\end{array}$ & $\begin{array}{l}64.7 \pm 4.3(37) \\
63.8 \pm 4.9(43)\end{array}$ & $\begin{array}{l}66.8 \pm 3.8(47) \\
63.6 \pm 3.6(19)\end{array}$ & $\begin{array}{l}67.2 \pm 4.7(43) \\
67.1 \pm 4.5(67)\end{array}$ & $\begin{array}{l}0.241 \\
0.782\end{array}$ & $\begin{array}{l}0.811 \\
0.072\end{array}$ & $\begin{array}{l}0.194 \\
0.093\end{array}$ \\
\hline BB rat & 16 weeks & Sciatic nerve & $\begin{array}{l}\text { Epi } \\
\text { Endo }\end{array}$ & $\begin{array}{l}68.1 \pm 2.8(74) \\
68.5 \pm 3.8(22)\end{array}$ & $\begin{array}{l}67.8 \pm 3.2(43) \\
65.5 \pm 4.0(29)\end{array}$ & & $\begin{array}{l}0.773 \\
0.171\end{array}$ & & \\
\hline BB rat & 16 weeks & Tail tendon & Distal & $67.9 \pm 2.2(48)$ & $69.4 \pm 2.4(46)$ & & 0.261 & & \\
\hline
\end{tabular}

of the groups. Numerical results for these comparisons are presented in Table 4. Overall, a period of $67 \mathrm{~nm}$ was observed. This is consistent with previous results $[34,40]$. Other techniques, including freeze-fracture followed by SEM, have revealed banding period as small as $61 \mathrm{~nm}$ [41], but this may be due to the presence of artifacts [42].

\section{Discussion}

\section{Quantification of collagen fibrils with AFM}

We have presented a model and a measuring procedure for AFM of structural collagens based on the cylindrical shape of collagen fibrils and their spatial arrangement. The results from the model agree well with actual tip traces for rat collagens, including the epineurium, the endoneurium, and the tail tendon.

\section{Changes in epineurial and endoneurial diabetic SD rat sciatic nerve collagen}

This work confirms earlier findings that the average diameters of endoneurial fibrillar collagens are larger in 12-week streptozotocin (STZ)-induced diabetes in SD rats than in controls, and presents the new evidence that average epineurial collagen fibril diameters are also larger. At least three separate mechanisms have been implicated in fibril enlargement in the presence of diabetes: (1) accumulation of AGES, which alters normal cross-link formation in the tertiary and quaternary structure of protein $[3,4,43,44]$, (2) increased mechanical stresses that result in upregulation of structural collagen genes [45-47], and (3) increased access to metabolic supplies such as glucose, which results in increased expression of basement membrane components $[48,49]$.

\section{Changes in epineurial, endoneurial, and tail diabetic $B B$ rat collagen}

The underlying causes of enlarged collagen fibril diameters in nerve and tail may be similar to those described for the SD model. Our results are in general agreement with those of other workers, with the major discrepancies between reported values arising from the location of fibers imaged. In comparisons between our results and those taken at similar locations, no significant discrepancies were found. The average diameter found for tail collagen of control BB rat was $125 \mathrm{~nm}$, which is consistent with the data presented by Gotoh [18]. Odetti et al. [15], in a similar study, reported higher values of $472 \mathrm{~nm}$ for diabetic rats and $302 \mathrm{~nm}$ for controls. These larger values probably resulted from their selection of the fascicle portion of the tendon for measurement; we measured fibrils from the fibrous layer (Figure 1b).

The significance of enlarged collagen is presently poorly understood. Previous in vitro results have shown that undeformed collagens, incubated with glucose at a concentration of $0.5 \mathrm{M}(9000 \mathrm{mg} / \mathrm{dL})$, also increase in diameter at a rate similar to the in vivo rate of collagen diameter increases in diabetic rat-tail tendon [15]. This concentration, however, is much greater than the physiological $(\sim 300 \mathrm{mg} / \mathrm{dL})$ concentration in diabetic tissue. Thus, given the much higher-thanphysiologic concentrations required in vitro, to replicate the magnitude of morphological change in vivo, other factors (e.g. increased mechanical stress due to elevated endoneurial fluid pressure [50]) may exacerbate the structural changes in the diabetic nerve.

Indeed, in vivo collagen metabolism rates vary widely [51], which would also influence any enlargement of collagens. Unfortunately, there is presently no way to correlate collagen type with collagen diameter in the three fibrillar collagens found in the nerve, namely, types I, III and V. Studies have indicated that excessive glucose results in upregulation in types III, but not in type I, in vitro [52], and that both types I and III are more prominent in human diabetic neuropathy [6]. This may be due to glucose-concentration-dependent collagen gene upregulation [53] as well as increased resistance to proteolysis [4]. These metabolic pathways will be a focus of future work.

We conclude that AFM tip artifacts must be accounted for in the reduction of collagen fibrillar diameter data, using standard (V-shaped standard, oxide-sharpened silicon nitride NanoProbe, or contact-etched silicon probes) tips. Our methodology appears to eliminate the tip effect by sampling several fibers simultaneously as shown in Figure A1 (a-d).

The cross-sectional curves of the AFM image of a group of aligned collagen fibrils is shown in Figure A2(b); it compares well with the model trace (Figure A2c). Values 


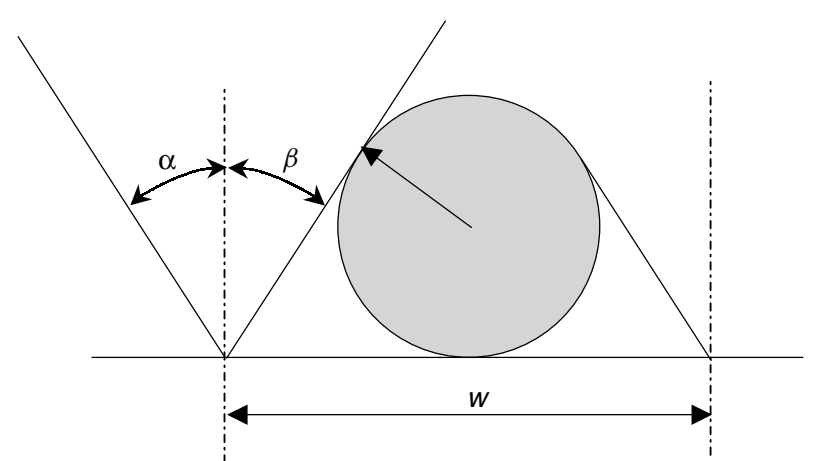

(a)

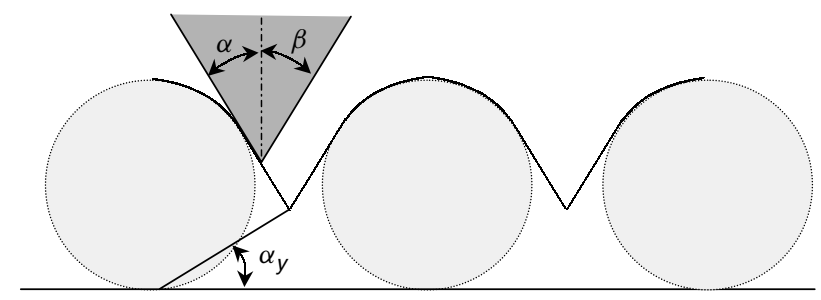

(c)

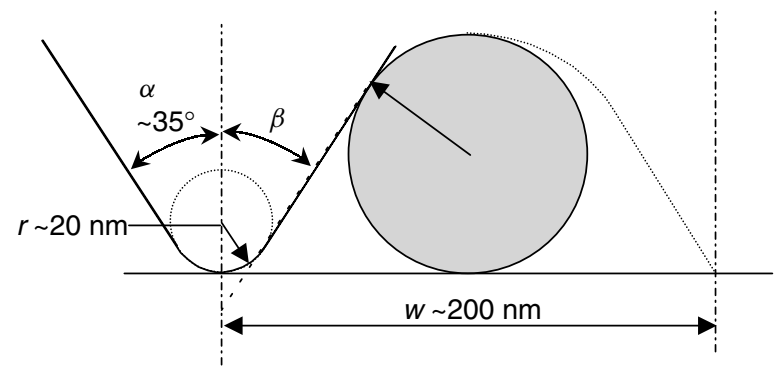

(b)

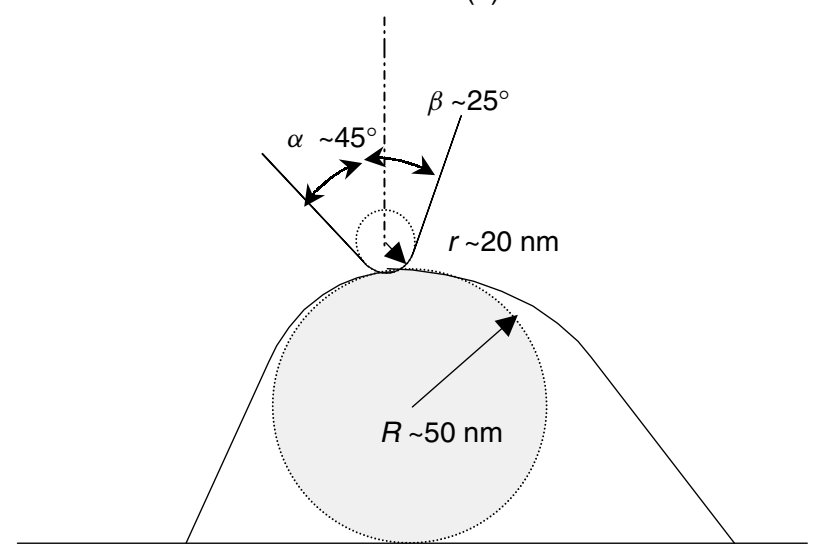

(d)

Figure A1. Summary of previous work geometries showing (a) perfectly sharp tip with no tip radius where tip contacts the substrate; (b) tip with finite radius; (c) tip with perfectly sharp tip where tip might not contact the substrate; and (d) tip with finite radius and a cantilever angle referenced in Table A1

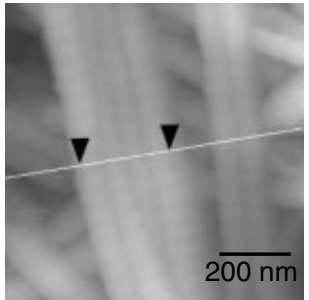

(a)

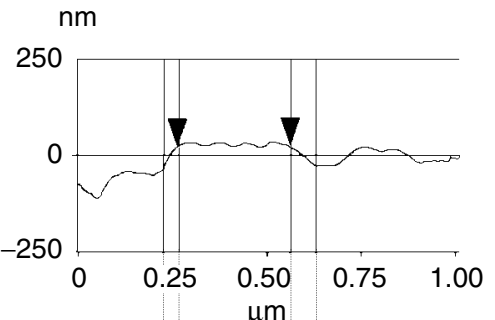

(b)

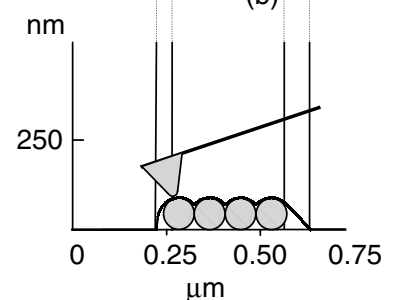

(c)
Figure A2. Trace example of multiple aligned collagen fibrils, showing (a) false-colored image; (b) DIcross section tool; and (c) tip trace from the model

obtained for the diameters of tail collagens agree with the results of Gotoh et al. [18], for example, who report a range of 30 to $210 \mathrm{~nm}$ with electron microscopy.

The differences found in the structural collagens of control and diabetic nerve will form the basis for future work.

\section{Appendix: analysis and simulation of tip artifacts and validation with actual images}

Various models have been developed for specific materials and tip geometries. Spherical samples have been modeled (e.g. $[25,28,29,32])$, several of which built directly on the work by Odin et al. [26] and Garcia et al. [30], as have AFM tips themselves [27,31]. Some of the relevant work is summarized in Table A1 and shown in Figure A1.

In this work, a model for single cylindrical collagen fibril is given, which is similar to the model given by Garcia et al. [30]. Tip traces from this model are validated with actual images.

By assuming that the tip is asymmetric and that the cantilever is angled, we derive an asymmetric tip path; data reduction is dependent upon the direction of approach of the tip to the cylinder. We denote the cylinder radius as $r_{c}$, tip radius as $r_{t}$, front angle as $\alpha$, back angle as $\beta$, and cantilever inclination angle as $\theta$. The apparent width of the image, denoted as $w$, is necessarily larger than $r_{c}$. The radius of tip path on the top, $r_{i}$, is necessarily larger than that of the cylinder. The tip trace can be deconstructed into three regions: straight line MN, arc MP, and straight line PQ. For the coordinate system shown in Figure A3(a), the description of lines MN and PQ 
Table A1. Models and assumptions made in other AFM studies

\begin{tabular}{|c|c|c|c|c|c|c|}
\hline Year & Author & $\begin{array}{c}\text { Variables } \\
\text { (present notation) }\end{array}$ & Tip shape & $\begin{array}{l}\text { Material } \\
\text { shape }\end{array}$ & $\begin{array}{l}\text { Material } \\
\text { system }\end{array}$ & Figure \\
\hline 2001 & Kato, et al. [24] & $\alpha=\beta, r_{t}$ & $\begin{array}{l}\text { Symmetric conic } \\
\text { tip with spherical } \\
\text { apex }\end{array}$ & Cylinder & Collagen fibrils & $\mathrm{A} 1$ (b) \\
\hline 2001 & Yang, D-Q. et al. [25] & $\alpha=\beta, \alpha_{y}$ & $\begin{array}{l}\text { Symmetric } \\
\text { triangular }\end{array}$ & Sphere & $\begin{array}{l}\text { Nanoceramic } \\
\text { particles }\end{array}$ & $A 1(a, c)$ \\
\hline 2000 & Odetti, P. et al. [15] & 0 & $\begin{array}{l}\text { Negligible tip } \\
\text { radius compared } \\
\text { with sample }\end{array}$ & Cylinder & Collagen fibrils & n.a. \\
\hline 1998 & Ramirez-Aguilar, K. A. et al. [29] & $\alpha=\beta, r_{t}, r_{c}$ & $\begin{array}{l}\text { Asymmetric } \\
\text { conical tip with } \\
\text { spherical apex }\end{array}$ & Sphere & $\begin{array}{l}\text { Silica and } \\
\text { polystyrene }\end{array}$ & $\mathrm{A} 1$ (d) \\
\hline 1997 & Garcia, V. J. et al. [30] & $\alpha, \beta, r_{t}$ & $\begin{array}{l}\text { Asymmetric } \\
\text { conical tip with } \\
\text { spherical apex }\end{array}$ & Sphere & n.a. & $\mathrm{A} 1$ (d) \\
\hline 1995 & Butt, H-J. [28] & $\alpha=\beta, r_{t}$ & $\begin{array}{l}\text { Conical tip with a } \\
\text { spherical apex }\end{array}$ & Sphere & Latex & $\mathrm{A} 1$ (b) \\
\hline 1994 & Odin, C. et al. [26] & $\begin{array}{l}\alpha=\beta, \lambda, r_{t} \\
\alpha=\beta, r_{t}, r_{c}\end{array}$ & $\begin{array}{l}\text { Symmetric conical } \\
\text { tip, parabolic tip, } \\
\text { Symmetric conical } \\
\text { tip with spherical } \\
\text { apex }\end{array}$ & HCP Sphere & Latex & $A 1(a, b)$ \\
\hline
\end{tabular}

n.a. (not applicable).

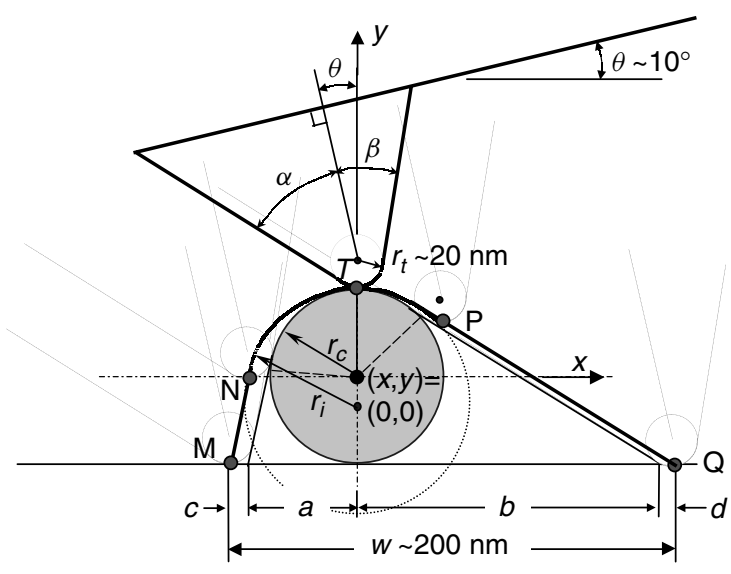

(a)

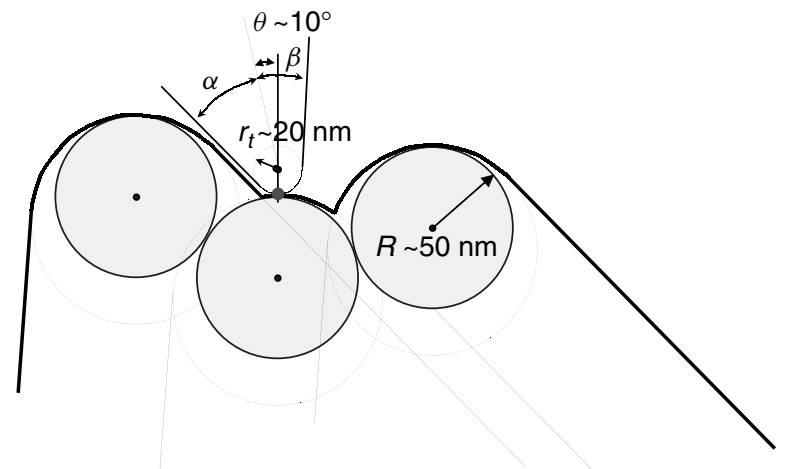

(b)

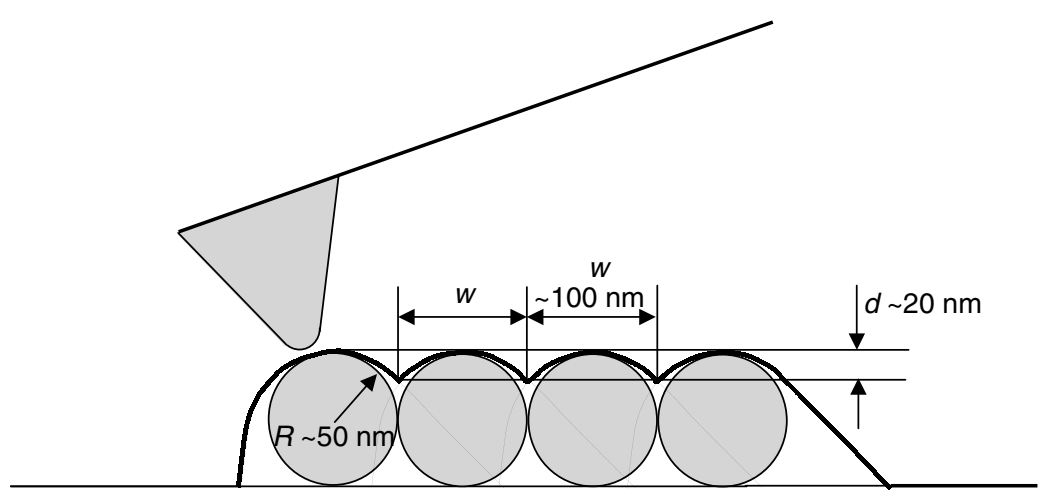

(c)

Figure A3. AFM tip tracing (a) single cylinder; (b) multiple misaligned; and (c) multiple aligned cylinders, showing actual cylinder outline and tip path 
Table A2. Geometry of contact line segments

\begin{tabular}{|c|c|c|c|c|}
\hline \multirow[t]{2}{*}{ Segment } & \multicolumn{2}{|c|}{ Starting point } & \multicolumn{2}{|c|}{ End point } \\
\hline & $x$ & $\mathrm{y}$ & $x$ & $y$ \\
\hline $\begin{array}{l}\mathrm{NM} \\
\mathrm{PQ}\end{array}$ & $\begin{array}{r}-\left(r_{c}+r_{t}\right) \cos (\beta-\theta) \\
\left(r_{c}+r_{t}\right) \cos (\alpha+\theta)\end{array}$ & $\begin{array}{r}-\left(r_{c}+r_{t}\right) \sin (\beta-\theta)-r_{t} \\
\left(r_{c}+r_{t}\right) \sin (\alpha+\theta)-r_{t}\end{array}$ & $\begin{array}{l}x_{\mathrm{N}}-I_{\mathrm{MN}} \sin (\beta-\theta) \\
x_{\mathrm{p}}+I_{\mathrm{PQ}} \sin (\alpha+\theta)\end{array}$ & $\begin{array}{l}y_{\mathrm{N}}-I_{\mathrm{MN}} \cos (\beta-\theta) \\
y_{\mathrm{p}}-I_{\mathrm{PQ}} \cos (\alpha+\theta)\end{array}$ \\
\hline
\end{tabular}

are given in Table A2. Arc NP has center point: $\left\{\begin{array}{l}x=0 \\ y=-r_{t}\end{array}\right.$ and radius $r_{i}$. The starting angle is $\alpha+\theta$, and the ending angle is $\pi-(\beta-\theta)$.

Assuming there is no deformation from contact forces, we have

$$
\begin{aligned}
r_{i}= & r_{c}+r_{t}, \\
\text { and } \quad w= & a+b+c+d \\
= & r_{c}\left[\frac{\cos (\beta-\theta)}{1-\sin (\beta-\theta)}+\frac{\cos (\alpha+\theta)}{1-\sin (\alpha+\theta)}\right] \\
& +r_{t}\left[\frac{\cos (\beta-\theta)}{1+\sin (\beta-\theta)}+\frac{\cos (\alpha+\theta)}{1+\sin (\alpha+\theta)}\right]
\end{aligned}
$$

We denote the lowest vertical point on the tip, relative to the specimen plane, as point $T$. This point coincides with the top center of the cylinder $(x, y)=\left(0, r_{c}\right)$ at the highest scan point. The sum $(a+c)$ is the horizontal projection of the path traversed by point $T$ as it approaches the cylinder from the left side (point $M$ ) to the top center of the cylinder, $(x, y)=\left(0, r_{c}\right)$. Chord $\mathrm{MN}$ is the line transcribed by the movement of the point $T$ as the tip moves from the base plane of the specimen to the first contact point between tip and cylinder. Distance $c$ is the horizontal projection of the path traversed by point $T$ as the tip is moved from point $\mathrm{M}$ to point $\mathrm{N}$ (whereupon the rounded portion of the tip changes the shape of the path to an arc, as the tip rounds the cylinder). Lengths $b$ and $d$ are analogous distances to $a$ and $c$ for the trailing portion of the tip path. Solving Equation A2 for cylinder radius $r_{c}$ we obtain

$$
r_{c}=\frac{\left\{w-r_{t}\left(\frac{\cos (\beta-\theta)}{1+\sin (\beta-\theta)}+\frac{\cos (\alpha+\theta)}{1+\sin (\alpha+\theta)}\right)\right\}}{\frac{\cos (\beta-\theta)}{1-\sin (\beta-\theta)}+\frac{\cos (\alpha+\theta)}{1-\sin (\alpha+\theta)}},
$$

Note that this model corresponds exactly to the one provided by Garcia et al. [30], with the trivial exception that we explicitly provide a variable $(\theta)$ for cantilever angle. We can relate the two models by modifying the expressions for the asymmetric angles describing the tip geometry to incorporate the effect of an angled cantilever, as

$$
\begin{aligned}
& \alpha^{\prime}=\alpha+\theta, \\
& \beta^{\prime}=\beta-\theta,
\end{aligned}
$$

where $\alpha^{\prime}$ and $\beta^{\prime}$ are the leading and trailing tip angles, respectively, of Garcia et al. [30]. Though they were modeling spheres, the problem becomes identical to the cylinder problem for measurements taken on 2D 'slices'. We explicitly define angle $\theta$ for convenience, because the cantilever is often angled with respect to the specimen plane in AFM apparati; for example, angles for the apparatus used in this study were $35^{\circ}, 35^{\circ}$ and $10^{\circ}$, for $\alpha, \beta$ and $\theta$, respectively.

With this model, the actual fibril radius $r_{c}$ can be calculated from $\alpha, \beta, \theta, r_{t}$ and $w$. The tip inclination, front, and back angles are generally provided by the manufacturer. However, the tip radius cannot be precisely controlled in the manufacturing process and frequently changes during the imaging process due to contamination [31]. In Reference [24], Kato et al. assumed the tip radius to be $50 \mathrm{~nm}$, and measured fibrils on flat surfaces.

In our specimens, fibrils were imaged in their native, closely packed state, resulting in traces such as that shown in Figure A3(b). As shown in Figure A3(c), the valley-tovalley distance is exactly equal to the diameter of the fibril, if neighboring fibrils are equi-sized, aligned and in tangential contact. We measured the valley-to-valley distances of several parallel and closely packed collagen fibrils, and reported the average distance as the diameter.

One possible deficiency of this approach is the potential overestimation of diameters due to the presence of gaps between neighboring fibrils. To minimize this error, three criteria were applied to the selection of imaging sites: good axial alignment of collagen fibrils within the site, small measured depth of valley between neighboring fibrils, and consistency in valley-to-valley distance and depth for the bundle of measurement. With our model and the tip geometry data from DI for Dimension Nanoprobe (DNP) tips, (tip radius: $20-60 \mathrm{~nm}, \alpha=\beta=35^{\circ}, \theta=10^{\circ}$ ), the allowable depth of valley was $5 \mathrm{~nm}, 15 \mathrm{~nm}$, and $25 \mathrm{~nm}$ for fibrils of radius $20 \mathrm{~nm}, 40 \mathrm{~nm}$, and $80 \mathrm{~nm}$, respectively. These maximum valley depths were used for endoneurial, epineurial, and tail tendon collagen fibrils, respectively.

Another possible source of error in using this model is improper alignment of tip relative to cylinder; that is, having the tip traverse a path over the cylinder, which is not orthogonal to its axis. If this occurs, the path itself would change, and diameters would be artificially large. To reduce this source of error in our own measurements, we were careful to take several sections for measurement using the DI sectioning tool, and to use images that minimized calculated diameters.

\section{Validations with actual image}

We found several types of arrangements of fibrils in our AFM work, including isolated single fibrils, aligned 
fibrils and misaligned groups of fibrils. In order to assess the validity of our model, we compared experimental and theoretical (per relations of Table A2) tip traces for each of these cases. It is important to note that our analysis of misaligned cylinders was performed using an iterative procedure for estimation of the height of each of the cylinders in the area. We show one example of this type here for illustration; we did not automate this approach because of the abundance of aligned bundles. We restricted our data set to the aligned-bundle regions, applying the criteria set out previously for maximum valley depths.

\section{Single cylinder}

A single collagen fibril was identified at the edge of a sample and imaged as shown in Figure A4(a). The crosssectional curve was obtained with the DI cross section tool as shown in Figure A4(b). The theoretical tip trace for a single cylinder is shown in Figure A4(c).

\section{Aligned cylinders with the same diameter}

Because the natural collagen fibrils from nerve tissue were tightly packed, groups of aligned collagen fibrils were observed (Figure A2). The cross-sectional curve of the AFM image of (a) is shown in Figure A2(b); it compares well with the model trace (Figure A2c).

\section{Misaligned cylinders of the same diameter}

For cases in which fibrils were not aligned, examples of traces of tip from the AFM image and model results are shown in Figure A5.

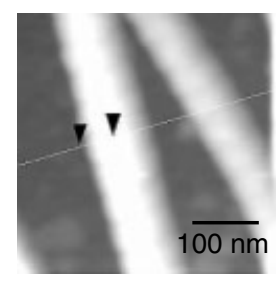

(a)

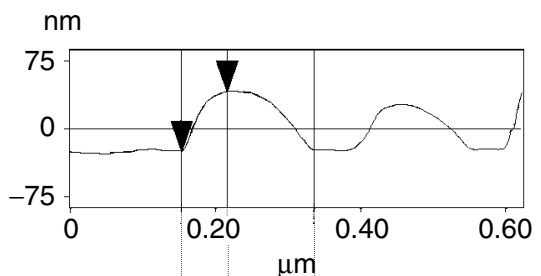

(b)

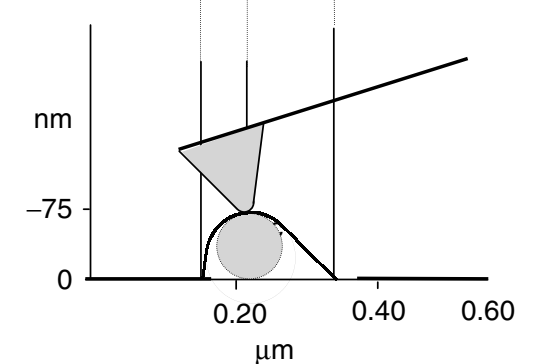

(c)

Figure A4. Trace example of a single collagen fibril, showing: (a) false-colored image; (b) DI cross section tool; and (c) tip trace from the model

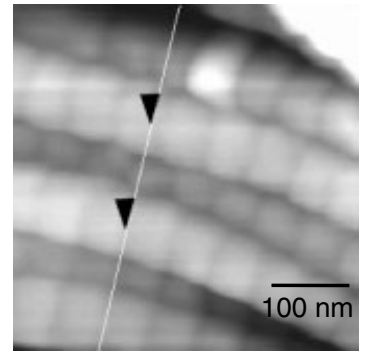

(a)

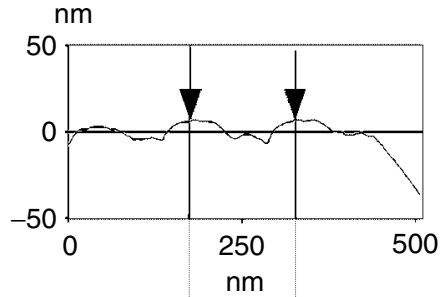

(b)

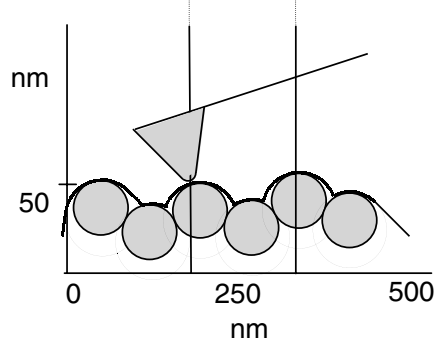

(c)
Figure A5. Trace example of multiple misaligned collagen fibrils, showing (a) false-colored image; (b) DI cross section tool; and (c) tip trace from the model

\section{Acknowledgements}

This work was supported by the Whitaker Foundation, the DARPA Synthetic Multifunctional Materials Program (Dr Leo Christodoulou and Dr Steve Fishman, Program Monitors) and by an NSF PECASE grant (Sastry); this funding is gratefully acknowledged.

\section{Symbols}

$\begin{array}{ll}\text { Symbol } & \text { Meaning } \\ w & \text { apparent fibril diameter } \\ r_{c} & \text { fibril radius } \\ r_{t} & \text { tip radius } \\ r_{i} & \text { tip trace radius } \\ \alpha & \text { leading tip angle } \\ \alpha_{y} & \text { angle from [23] } \\ \beta & \text { trailing tip angle } \\ \lambda & \text { parabolic tip parameter of [26] } \\ \theta & \text { cantilever angle }\end{array}$

\section{References}

1. Greene DA, Feldman EL, Stevens MJ, Sima AAF, Albers JW, Pfeifer MA. Diabetic neuropathy. In Ellenberg \& Rifkin's Diabetes Mellitus, Porte D, Sherwin R, Rifkin H (eds). Appleton \& Lange: Stamford, CT, 1997; 1009-1076.

2. DCCT-Diabetes Control and Complications Trial Research Group. The effect of intensive diabetes therapy on the development of progression of neuropathy. Ann Intern Med 1995; 122: 561-568.

3. Amudeswari S, Liang JN, Chakrabarti B. Polar-apolar characteristics and fibrillogenesis of glycosylated collagen. Coll Relat Res 1987; 7: 215-223.

4. Sensi M, Pricci F, Pugliese G, et al. Role of advanced glycation end-products (AGE) in late diabetic complications. Diabetes Res Clin Pract 1995; 28: 9-17. 
5. Sanders JE, Goldstein BS. Collagen fibril diameters increase and fibril densities decrease in skin subjected to repetitive compressive and shear stresses. J Biomechanics 2001; 34: $1581-1587$.

6. Bradley JL, King RH, Muddle JR, Thomas PK. The extracellular matrix of peripheral nerve in diabetic polyneuropathy. Acta Neuropathol 2000; 99: 539-546.

7. Schmitt FO, Hall CE, Jakus MA. Electron microscope investigations of the structure of collagen. J Cell Comp Biol 1942; 20: 11-33.

8. Thomas PK, Berthold C-H, Ochoa J. Microscopic anatomy of the peripheral nervous system. In Peripheral Neuropathy (3rd edn), Dyck PJ, Thomas PK, Griffin JW, Low PA, Poduslo JF (eds). W.B.Sanders: Philadelphia, 1993; 28-91.

9. Baranauskas V, Vidal BC, Parizotto NA. Observation of geometric structure of collagen molecules by atomic force microscopy. Appl Biochem Biotech 1998; 69: 91-97.

10. Revenko I, Sommer F, Min DT, Garrone R, Franc JM. Atomic force microscopy study of the collagen fibre structure. Biol Cell 1994; 80: 67-69.

11. Ushiki T, Ide C. 3-dimensional organization of the collagen fibrils in the rat sciatic-nerve as revealed by transmission electron and scanning electron-microscopy. Cell Tissue Res 1990; 260: $175-184$

12. Gotoh T, Sugi Y. Electron-microscopic study of the collagen fibrils of the rat tail tendon as revealed by freeze-fracture and freeze-etching techniques. Cell Tissue Res 1985; 240: 529-534.

13. Gamble HJ, Eames RA. An electron microscope study of the connective tissues of human peripheral nerves. J Anat 1964; 98: $655-663$

14. Thomas PK. The connective tissue of peripheral nerve: an electron microscope study. J Anat, London 1963; 97: 35-44.

15. Odetti P, Aragno I, Rolandi R, et al. Scanning force microscopy reveals structural alterations in diabetic rat collagen fibrils: role of protein glycation. Diabetes Metab Res Rev 2000; 16: 74-81.

16. Muona P, Jaakkola S, Salonen V, Peltonen J. Diabetes induces the formation of large diameter collagen fibrils in the sciatic nerves of BB rats. Matrix 1989; 9: 62-67.

17. Johnson PC, Brendel K, Meezan E. Human diabetic perineurial basement membrane thickening. Lab Invest 1981; 44: 265-270.

18. Gotoh T, Murashige N, Yamashita K. Ultrastructural observations on the tendon sheath of the rat tail. $J$ Electron Microsc 1997; 46: 247-252.

19. Binnig G, Quate CF, Gerber CH. Atomic force microscope. Phys Rev Lett 1986; 56: 930-933.

20. Drake B, Prater CB, Weisenhorn AL, et al. Imaging crystals, polymers, and processes in water with the atomic force microscope. Science 1989; 243: 1586-1589.

21. Morris VJ, Kirby AR, Gunning AP. Atomic Force Microscopy for Biologists, Imperial College Press: London, UK, 1999.

22. Meller D, Peters K, Meller K. Human cornea and sclera studied by atomic force microscopy. Cell Tissue Res 1997; 288: 111-118.

23. Paige MF, Rainey JK, Goh MC. A study of fibrous long spacing collagen ultrastructure and assembly by atomic force microscopy. Micron 2001; 32: 341-353.

24. Kato K, Bar G, Cantow HJ. The interplay surface microtopography and mechanics of type I collagen fibrils in air and aqueous media: an atomic force microscopy study. Eur Phys $J E$ 2001; 6: 7-14.

25. Yang D-Q, Xiong Y-Q, Guo Y, Da D-A, Lu W-G. Sizes correction on AFM images of nanometer spherical particles. J Mater Sci 2001; 36: 263-267.

26. Odin C, Aime JP, Kaakour ZE, Bouhacina T. Tip's finite size effects on atomic force microscopy in the contact mode: simple geometrical considerations for rapid estimation of apex radius and tip angle based on the study of polystyrene latex balls. Surf Sci 1994; 317: 321-340.

27. Villarrubia JS. Scanned probe microscope tip characterization without calibrated tip characterizer. J Vac Sci Technol, B 1996; 14: 1518-1521.

28. Butt H-J, Gerharz B. Imaging homogeneous and composite latex particles with an atomic force microscope. Langmuir 1995; 11: 4735-4741.

29. Ramirez-Aguilar KA, Rowlen KL. Tip characterization from AFM images of nanometric spherical particles. Langmuir 1998; 14: $2562-2566$
30. Garcia VJ, Martinez L, Briceno-Valero JM, Schilling CH. Dimensional metrology of nanometric spherical particles using AFM. Probe Microsc 1997; 1: 107-116.

31. Bykov V, Gologanov A, Shevyakov V. Test structure for SPM tip shape deconvolution. Appl Phys A 1998; 66: 499-502.

32. Markiewicz P, Goh MC. Atomic-force microscopy probe tip visualization and improvement of images using a simple deconvolution procedure. Langmuir 1994; 10: 5-7.

33. Friede RL, Bischhausen R. The organization of endoneurial collagen in peripheral nerves as revealed with the scanning electron microscope. J Neurol Sci 1978; 38: 83-88.

34. Aragno I, Odetti F, Cavalleri O, Rolandi R. Structure of rat tail collagen examined by atomic force microscope. Experientia 1995; 51: 1063-1067.

35. Guberski DL. Diabetes-prone and diabetes-resistant BB rats: animal models of spontaneous and virally induced diabetes mellitus, lymphocytic thyroiditis, and collagen-induced arthritis. ILAR News 1994; 35: 29-36.

36. Pop-Busui R, Sullivan KA, Van Huysen C, et al. Depletion of taurine in experimental diabetic neuropathy: implications for nerve metabolic, vascular, and functional deficits. Exp Neurol 2001; 168: 259-272.

37. Box GEP, Hunter WG, Hunter JS. Comparing two treatments. In Statistics for Experimenters, Box GEP, Hunter WG, Hunter JS (eds). Wiley: New York, 1978; 21-56.

38. Lewis B. 2002; http://nimitz.mcs.kent.edu/ blewis/stat/tTest. html [25 June 2002].

39. Press WH, Flannery BP, Teukolsky SA, Vetterling WT. Do two distributions have the same means or variances? In Numerical Recipes: The Art of Scientific Computing, Press WH, Flannery BP, Teukolsky SA, Vetterling WT (eds). Cambridge University Press: New York, 1986; 464-469.

40. Christiansen DL, Huang EK, Silver FH. Assembly of type I collagen: fusion of fibril subunits and the influence of fibril diameter on mechanical properties. Matrix Biol 2000; 19: 409-420.

41. Belton JC, Michaeli D, Fudenberg HH. Freeze-etch study of collagen I. Native collagen from tendon and lung of rats. Arthritis Rheum 1975; 18: 443-450.

42. Sleytr UB, Robards AW. Understanding the artefact problem in freeze-fracture replication: a review. J Microsc 1982; 126 Pt1: 95-105

43. Cooper ME, Thallus V, Forbes J, et al. The cross-link breaker, $\mathrm{N}$-phenacylthiazolium bromide prevents vascular advanced glycation end-product accumulation. Diabetologia 2000; 43: 660-664.

44. Rellier N, Ruggiero-Lopez D, Lecomte M, Lagarde M, Wiernsperger N. vitro and in vivo alterations of enzymatic glycosylation in diabetes. Life Sci 1999; 64: 1571-1583.

45. Schild C, Trueb B. Mechanical stress is required for high-level expression of connective tissue growth factor. Exp Cell Res 2002; 274: 83-91.

46. Chiquet M. Regulation of extracellular matrix gene expression by mechanical stress. Matrix Biol 1999; 18: 417-426.

47. Chiquet M, Matthisson M, Koch M, Tannheimer M, ChiquetEhrismann R. Regulation of extracellular matrix synthesis by mechanical stress. Biochem Cell Biol 1996; 74: 737-744.

48. Cagliero E, Roth T, Roy S, Maiello M, Lorenzi M. Expression of genes related to the extracellular matrix in human endothelial cells. J Biol Chem 1991; 266: 14244-14250.

49. Spiro MJ, He Q, D'Autilia MLD. Effect of high glucose on formation of extracellular matrix components by cultured rat heart endothelial cells. Diabetologia 1995; 38: 430-436.

50. Powell HC, Costello ML, Myers RR. Endoneurial fluid pressure in experimental models of diabetic neuropathy. $J$ Neuropathol Exp Neurol 1981; 40: 613-624.

51. Bornstein P, Sage H. Structurally distinct collagen types. Annu Rev Biochem 1980; 49: 957-1003.

52. Benazzoug Y, Borchiellini C, Labat-Robert J, Robert L, Kern P. Effect of high-glucose concentrations on the expression of collagens and fibronectin by fibroblasts in culture. Exp Gerontol 1998; 33: 445-455.

53. Muona P, Peltonen J, Jaakkola S, Uitto J. Increased matrix gene expression by glucose in rat neural connective tissue cells in culture. Diabetes 1991; 40: 605-611. 